\title{
Off-farm employment and agricultural land use efficiency in China
}

\author{
Qianyu Zhao ${ }^{\mathrm{a}}$, Helen X.H. Bao ${ }^{\mathrm{b}{ }^{* 1}}$, Zhanlu Zhang ${ }^{\mathrm{c}}$ \\ a Department of Land and Real Estate Management, School of Public Administration, Sichuan University of China, \\ No. 24 South Section1, Yihuan Road, Chengdu 610065, PR China \\ ${ }^{b}$ Department of Land Economy, University of Cambridge, Cambridge CB3 9EP, UK \\ ${ }^{\mathrm{c}}$ Department of Land and Real Estate Management, School of Public Administration and Policy, Renmin \\ University of China, No. 59 Zhongguancun Street, Beijing 100872, PR China
}

\begin{abstract}
The non-agricultural employment transfer of the rural labor force has fundamentally changed the labor input in China in recent decades. A good understanding of how the off-farm employment of rural laborers affects agricultural land use in China is needed. We use the Driscoll and Kraay standard errors fixed effects model to investigate the relationship between rural laborers' off-farm employment and agricultural land use efficiency based on a panel data of 1,961 counties in China. We find that the distribution of county-level agricultural land use efficiency is heavily skewed to the right, with many counties below the national average efficiency level. We also identify a robust U-shaped relationship between off-farm employment and the change in agricultural land use efficiency, indicating that the substitution effect of capital and technology for rural labor has changed from weak to strong. The findings have important policy implications for the joint reform of the household registration (hukou) system and the rural land use system (i.e., the Three Rights Separation Reform) in China. Using the criteria derived from empirical analysis, we also perform content analysis to assess 20 rural land use policies implemented between 2014 and 2020. We find that these documents covered the three important areas to improve rural land use efficiency, that is, rural-urban mobility, rural land rights market development, and rural land rights protection. Although a synergy among the three areas has not yet been achieved, the central government has already put in place policies to enable and support coordinated actions in the three areas. The lessons learned from China also serve as a helpful reference for addressing the challenge of rural labor loss in other developing countries.
\end{abstract}

Keywords: migration; agricultural land use change; land use efficiency; U-shaped effect

\section{Acknowledgements}

We are grateful for the financial support from the Economic and Social Research Council (Grant No. ES/P004296/1), the National Natural Science Foundation of China (Grant No. 71661137009), and the Youth Project (Grant No. 2019CJY035).

\footnotetext{
${ }^{*}$ Corresponding author. Tel: +44 1223337116

Email address: zhaoqianyu@ruc.edu.cn (Q. Zhao); hxb20@cam.ac.uk (H. Bao); zhangzhanlu@ruc.edu.cn (Z. Zhang)
} 


\title{
Off-farm employment and agricultural land use efficiency in China
}

\begin{abstract}
The non-agricultural employment transfer of the rural labor force has fundamentally changed the labor input in China in recent decades. A good understanding of how the off-farm employment of rural laborers affects agricultural land use in China is needed. We use the Driscoll and Kraay standard errors fixed effects model to investigate the relationship between rural laborers' off-farm employment and agricultural land use efficiency based on a panel data of 1,961 counties in China. We find that the distribution of county-level agricultural land use efficiency is heavily skewed to the right, with many counties below the national average efficiency level. We also identify a robust U-shaped relationship between off-farm employment and the change in agricultural land use efficiency, indicating that the substitution effect of capital and technology for rural labor has changed from weak to strong. The findings have important policy implications for the joint reform of the household registration (hukou) system and the rural land use system (i.e., the Three Rights Separation Reform) in China. Using the criteria derived from empirical analysis, we also perform content analysis to assess 20 rural land use policies implemented between 2014 and 2020. We find that these documents covered the three important areas to improve rural land use efficiency, that is, rural-urban mobility, rural land rights market development, and rural land rights protection. Although a synergy among the three areas has not yet been achieved, the central government has already put in place policies to enable and support coordinated actions in the three areas. The lessons learned from China also serve as a helpful reference for addressing the challenge of rural labor loss in other developing countries.
\end{abstract}

Keywords: migration; agricultural land use change; land use efficiency; U-shaped effect

\section{Introduction}

Rural-to-urban migration is a persistent phenomenon in the urbanization and industrialization process of most countries (Ledent, 1982; Phimister and Roberts, 2006). The reallocation of rural laborers between urban and rural areas generates chain economic and political institutions (de Brauw et al., 2014). There is no doubt that this migration has far-reaching implications for the development of a country and beyond (Chauvin et al., 2017). The outflow of rural laborers, characterized by off-farm employment, has raised concerns about agricultural production and rural decline, especially in China (Chen et al., 2014; Liu and Li, 2017). For example, the number of rural migrant workers in 2017 reached 288.36 million, accounting for $37.17 \%$ of the total number of employees in the country ${ }^{1}$. In the absence of a working rural land transfer market in China, the great number of rural laborers flowing out of the countryside has raised concern about food security: "Who will plant the crops in the future" (Boland, 2000; Smil, 1995; Xu et al., 2019). However, statistics show that China's agriculture sector has not shown any significant loss of rural labor. In contrast, the crop planting area, grain output and agricultural production in general have all shown a continuous trend of rapid growth. Should Chinese policy makers and scholars be

\footnotetext{
1 The bulletin is issued yearly by the National Bureau of Statistics, the official statistical agency of China.
} 
concerned about off-farm employment of rural laborers?

To answer this challenging question, it is necessary to isolate the net effect of rural laborers' off-farm employment on agricultural land use in China. Using survey data from rural households, some scholars have identified two effects that are working in opposite directions, i.e., the negative lost-labor effect and the positive income effect (e.g., Feng et al., 2010; Rozelle et al., 1999; Taylor et al., 2003). The negative lost-labor effect refers to the fact that off-farm employment reduces the labor supply for agricultural production. This is particularly true in China because most of the migrating rural residents are young males (Gai et al., 2014; Wang et al., 2017). On the other hand, the remittances sent home by migrants also enable households to overcome the credit and insurance constraints in China's less economically developed rural areas (de Brauw and Rozelle, 2008; Taylor et al., 2003), presenting the positive income effect. For instance, rural households can use remittances to purchase fertilizers and machinery for agricultural production, which could compensate for the lost-labor effect to a certain extent (Ji et al., 2012; Mendola, 2008; Wang, 2015). The net effects of rural laborers' off-farm employment on agricultural production depend on how one effect offsets another. However, which effect dominates is still unclear. The objective of our study is to bridge this gap in the literature.

We extend previous studies by using a system approach. Specifically, we consider both the lost-labor and the income effects in one unified framework. This setup is necessary given China's institutional background. First of all, rural agricultural land in China belongs to the village collectives. Rural households have only the land contract and management rights. This arrangement of land property rights among rural residents often prevents rural residents from completely cutting the ties with their allocated rural land, even if they are working in cities as migrant workers. Second, China's the household registration (hukou) system prevents rural migrants from accessing educational, medical, and social welfare resources in cities where they are working. In this sense, the contract and management rights of agricultural land not only protect agricultural production and rural employment but also have a pivotal social security function for rural labors (Liu, 2018). Therefore, the impact of off-farm employment on agricultural land use efficiency is rather complex, and the lost-labor and income effects should not be studied in isolation. Our theoretical framework effectively captures the interaction between the two effects.

On the empirical front, our innovations are the use of panel data from nearly 2,000 counties in China, and the adoption of the Driscoll and Kraay standard errors fixed effects model. Previous studies on the effect of off-farm employment in China adopted cross-sectional data primarily, and rarely considered non-linear relationship between land use efficiency and off-farm employment. Our empirical strategy, on the other hand, is capable of capturing the dynamic and complex effect of off-farm employment. We find that the distribution of county-level agricultural land use efficiency is heavily skewed to the right, with many counties below the national average efficiency level. We also identify a robust U-shaped relationship between rural laborers' off-farm employment and the change in agricultural land use efficiency, indicating that the substitution effect of capital and technology for rural labor has changed from weak to strong. The incorporative effects of the individual transfer mode and the smallholder management scale are identified as the main drivers of this relationship. The findings have important policy implications for the joint reform of the household registration (hukou) system and the rural land use system (the Three Rights Separation Reform) in China. We also assessed 20 rural land use policies implemented between 2014 and 2020 based on the criteria derived from the empirical analysis. 
The lessons learned from China also serve as a helpful reference to address the challenge of rural labor loss in other developing countries.

The rest of the paper is structured as follows. Section two presents a theoretical framework to study the relationship between off-farm employment and agricultural land use efficiency. Section three introduces the empirical models and data; Section four discusses the empirical findings. Section five concludes by drawing policy implications and discussing future research directions.

\section{Theoretical framework}

\subsection{Two intertwining effects}

Rural laborers' off-farm employment affects agricultural land use both directly and indirectly. In the process of rural labor transfer, not only are the labor input quantity and structure changed, but the input-output relationship of agricultural land use is also reshaped through substitution among input factors (Zhong et al., 2016). Many studies have confirmed the substitution effect of capital on labor in agricultural production (e.g., Yang et al., 2013;Ji et al., 2017, 2012), through which the transfer of labor triggers a chain of far-reaching effects that finally affect agricultural land use (Chen et al., 2014).

The literature has identified two main effects of the off-farm employment of rural laborers on agricultural land use, i.e., the lost-labor effect and the income effect. The net effect of rural laborers' off-farm employment on agricultural land use depends on how one effect offsets another. These two effects are combined to determine the substitution relationship between capital and labor and, ultimately, the dynamics between the off-farm employment of rural laborers and agricultural land use. When the income effect is strong enough to counterbalance the negative impact of lost labor, the substitution relationship of capital and labor will be enhanced, and the off-farm employment of rural laborers will be a gain for agricultural production. In contrast, when the income effect is weak and cannot offset the negative impact of lost labor, the substitution relationship will be weakened. Agricultural production based on rural households will be faced with labor supply constraints, which will evolve into a drain in the agricultural sector. Thus, the two intertwining effects would work together to form a nonlinear relationship between rural laborers' off-farm employment and agricultural land use efficiency.

To further illustrate the nonlinear relationship, we follow the work of Phimister and Roberts (2006) and Zhao (1999), and make some modifications according to China's situation. Without loss of generality, the agricultural land production of rural households is summarized as follows:

$$
y=f\left(l_{f}, k, n\right)
$$

where $l_{f}$ stands for farm labor input, and $k, n$ represent capital and agricultural land inputs, respectively. For simplicity, we assume that rural households allocate a fixed labor resource, $\bar{L}$, between agricultural production and off-farm employment. Then, we can derive the objective function of the household as follows:

$$
\max \left\{\pi=\rho f\left(l_{f}, k, n\right)-r k-s n+\omega\left(\bar{L}-l_{f}\right)\right\}
$$

where $\rho$ denotes the price vector of agricultural products, $r$ is the rental rate of capital inputs and $s$ is the rental rate of agricultural land resources, $\omega$ is the wage rate of the off-farm labor force, and $\bar{L}-l_{f}$ represents the number of off-farm laborers in rural households. In China, rural agricultural land belongs to the village collectives and is allocated to rural households for free according to membership. Therefore, the area of agricultural land per household can be treated as exogenous, and $s n$ can be eliminated from equation (2) because $s$ is nearly zero. In addition, 
rural households face the constraint of a minimum labor supply that must be allocated to farming. According to the legal provisions concerning rural land contracting, rural households risk losing contracting rights if the land allocated to them is left idle for a certain number of years. We assume that the minimum labor supply of the household is $L_{\min }$. The objective function of the household is thus modified as follows:

$$
\left\{\begin{array}{c}
\max \left\{\pi=\rho f\left(l_{f}, k, \bar{n}\right)-r k+\omega\left(\bar{L}-l_{f}\right)\right\} \\
\text { s. } b . L_{\min } \leq l_{f} \leq \bar{L}
\end{array}\right\}
$$

According to our target programming constraints, the Kuhn-Tucker first-order conditions are used to solve the optimization problem. We can obtain the following results:

$$
\rho f_{l_{f}}\left(l_{f}, k, \bar{n}\right)-\omega=\left\{\begin{array}{ll}
>0 & \text { if } l_{f}=\bar{L} \\
<0 & \text { if } l_{f}=L_{\min } \\
=0 & \text { if } L_{\min } \leq l_{f} \leq \bar{L}
\end{array}\right\}
$$

Deriving equation (4), with the increasing off-farm employment of the rural labor force and the corresponding decline of farm labor input, the first derivative value of $f\left(l_{f}, k, n\right)$ is segmented into different directions similarly to the objective function $\pi$.

$$
f_{l_{f}}\left(l_{f}, k, \bar{n}\right)=\left\{\begin{array}{ll}
>\frac{\omega}{\rho} & \text { if } l_{f}=\bar{L} \\
<\frac{\omega}{\rho} & \text { if } l_{f}=L_{\min } \\
=\frac{\omega}{\rho} & \text { if } L_{\min } \leq l_{f} \leq \bar{L}
\end{array}\right\}
$$

Therefore, the change in labor input could have a nonlinear impact on agricultural production. However, it is not straightforward to determine the specific nonlinear shape of this effect because it is difficult to capture the substitution relationship between $l_{f}$ and $k$. The complex relationship between the two intertwining effects is further illustrated by the two competing theories in the following section.

\subsection{Two competing theories}

The non-agricultural employment transfer of the rural labor force has changed the labor input for agricultural land, which in turn affects the input-output relationship of agricultural land. That is, the transfer of rural labor affects the production efficiency of agricultural land. In this case, the effect depends on the relationship between the labor supply and agricultural land use efficiency. The key is whether the rural labor supply is surplus relative to the labor demand of farmland use. According to the "dual economy" theory developed by Lewis (1954) and elaborated by Fei and Rains (1964), there is extensive "disguised" unemployment of rural labor where the marginal productivity is negligible, zero, or even negative in the agricultural sector at the beginning of industrialization. Therefore, the outflow of surplus rural labor will not affect the level of farmland production but will instead improve the farmland input-output relationship. However, with the advance of industrialization, the continuous outflow of rural labor attracted by the industrial sector changes the situation. The rural labor force needed for agricultural land use becomes scarce. If other conditions remained unchanged, farmland output would decrease, and rural land use efficiency would be negatively affected. Thus, the change in land use efficiency might have an inverted U-shape pattern as the level of rural-to-urban migration increases (Fig. 1). 


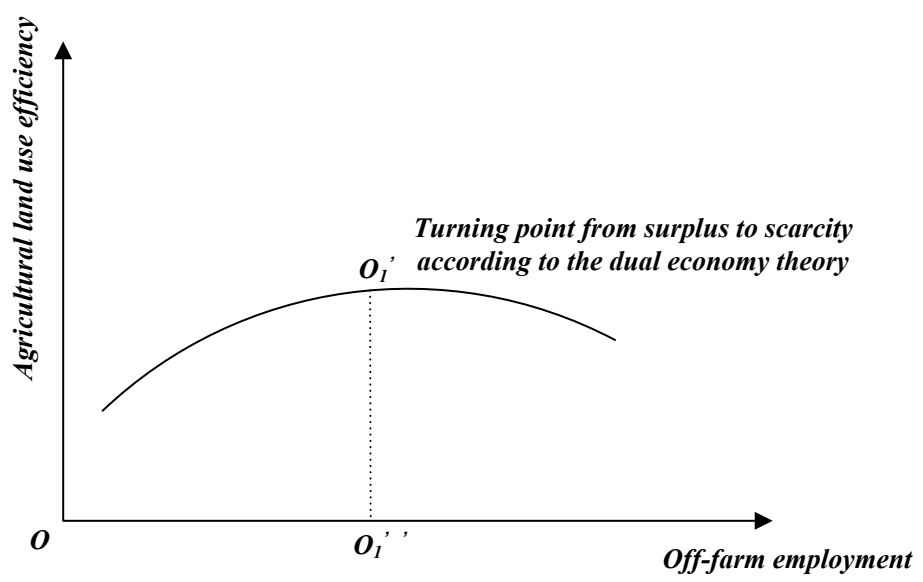

Figure 1. The inverted U-shape relationship under Lewis (1954)

Different from the disguised unemployment hypothesis under the dual economy theory, Schultz (1964) claimed that farmers in developing countries are "poor but efficient", meaning that they make efficient use of their limited resources to use agricultural land. The peculiarities of traditional agricultural production modes determine that there should be no disguised unemployment in rural areas. Instead, farmers make full use of and reasonably allocate limited resources for agricultural production, while the reason for poverty or low agricultural production efficiency lies in the lack of adequate resources, such as capital and technology (Abler and Sukhatme, 2006). Under the constraint input of capital, technology and other factors, the off-farm employment transfer of rural laborers will reduce the output of agricultural land and negatively affect the efficiency of agricultural land use. However, as rural labor moves out of the agricultural sector and into urban industrial areas, there are advances in machinery, fertilizers, farming organizations and production techniques, which increase agricultural yield level, reduce the labor required per unit area, and further promote agricultural land use efficiency (Chang, 2012). In this case, the impact of rural laborers' off-farm employment on agricultural land use efficiency would follow a U-shaped trend (Fig. 2).

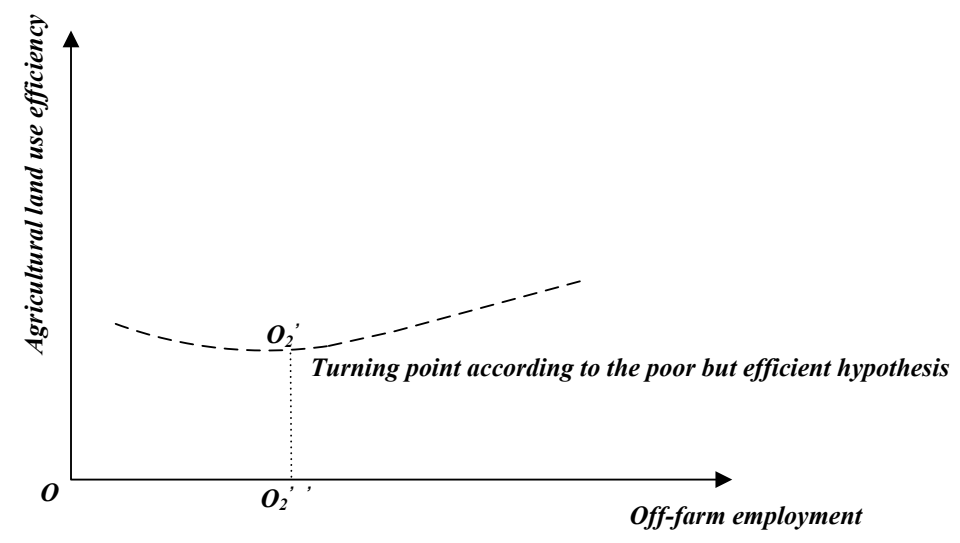

Figure 2. The U-shaped relationship under Schultz (1964)

Given the two possible nonlinear impacts, which is the case in China? On the one hand, China's unique urban-rural dual economic system seems to support the explanation of the dual economy theory (Zhang et al., 2011). For example, the sustained slowdown in the economy since 2010 coincides with the disappearance of China's "demographic dividend" (Cai, 2018). On the 
other hand, the pattern of agricultural land use is small farm production under the household contract responsibility system. In the absence of a rural credit market, rural households have limited capital input for agricultural production, and the family labor is engaged in demanding agricultural work, with even the children having to help in the field before the 2000s (Xu, 2014). Under China's traditional agricultural production mode, it is hard to say that there is a surplus of rural labor. Thus, the scientific answer to this research question must be based on empirical evidence from China. However, existing empirical studies based on farm household cross-sectional survey data cannot capture the change over time, which results in some conflicting conclusions in the literature. We therefore propose a different empirical implementation strategy to test the two competing theories in China.

\section{Empirical implementation and data}

\subsection{Measuring agricultural land use efficiency}

Agricultural land in China has a broad connotation. According to the Land Administration Law of China, agricultural land refers to the land directly used for agricultural production, including arable land, woodland, garden land and pit ponds (the Central People's Government of the People's Republic of China, 2004). Namely, the range of agricultural land far exceeds the range of arable land used for plant cultivation; the frequent use of the term without specification leads to the misuse of some statistical indicators ${ }^{2}$. Therefore, it is crucial to define the scope of agricultural land in China before selecting indicators and building models.

Agricultural land use efficiency is an index used to measure agricultural productivity (Reddy and Ramanaiah, 2002) and reflects the input-output composition relationship of agricultural production. Studies have adopted two methods (see, e.g., Allen, 2000; Feng, 2008; Glaeser, 2014; Mubarak and Derek, 1991) to measure efficiency: the single factor productivity method (such as crop yield per unit area, agricultural product per unit area, and labor productivity) and the total factor productivity (TFP) method based on parametric or nonparametric models. Although the former method can directly reflect specific factor productivity, it cannot reflect the impact of other

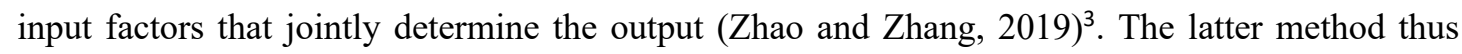
has become prevalent, among which data envelopment analysis (DEA) seems to be more preferable to a stochastic frontier approach when dealing with multiple agricultural inputs and outputs (Helfand, 2003). This study uses the hybrid model, an innovative DEA model that considers the substitution relationship of input factors, to estimate the distance between observed input-output combinations and a best practice frontier and calculate the agricultural land use efficiency. The hybrid model judges the substitutability of the input factors in agricultural production by analyzing their quantitative proportionality, that is, the correlation between projected values on the production frontier. The input-oriented goal programming is specified as follows:

\footnotetext{
2 Some key statistical agricultural indicators in China, such as total power of agricultural machinery and total amount of fertilizer, are based on the data from crop planting, forestry, animal husbandry and fisheries, but they are often misused only for crop planting input analysis.

3 Additionally, we use the single factor productivity method for a robustness test in our study.
} 


$$
\left\{\begin{array}{l}
\min \psi=1-\frac{m_{1}}{m}(1-e f f)-\frac{1}{m} \sum_{\mathrm{i}=1}^{m_{2}} s_{i}^{N-} / I_{i k}^{N} \\
\text { s.t. } I^{R} \lambda+\mathrm{s}^{\mathrm{R}-}-e f f I_{k}^{R}=0 \\
I^{N} \lambda+\mathrm{s}^{\mathrm{N}-}=I_{k}^{N} \\
0 \lambda \geq \mathrm{O}_{k} \\
\lambda, \mathrm{s}^{-} \geq 0
\end{array}\right\}
$$

where $\psi$ denotes the largest eigenvalue of the correlation coefficient matrix of the nonradial input indicator projection value. eff is the efficiency value defined in a relative sense. The superscript $R$ represents the radial indicators, while $N$ denotes the nonradial indicators. Similarly, $I$ represents the input factors, while $O$ denotes the output factors. $m$ is the number of input factors, where $m_{1}$ is the number of radial input indicators and $m_{2}$ is the number of nonradial indicators. $s^{-}$is a slack variable that reflects the redundancy rate of the input, and $\lambda$ is the combination coefficient. In this study, we use the hybrid model to estimate the agricultural land use efficiency of 1,961 counties in China and further include efficiency as the dependent variable in the empirical models.

\subsection{Modeling the impact of off-farm employment}

Our empirical analysis focuses on the impacts of rural labor off-farm employment on agricultural land use efficiency in China. The construction of the panel econometric model is based on the theoretical analysis of the impact characteristic and framework. We follow a reduced form equation that requires less information but uses the county-level panel data to control for unobserved heterogeneity and potential endogeneity of off-farm employment and can therefore be used to identify the extent of efficiency change. The reduced form can be specified as follows:

$$
Y_{i t}=a+\beta L_{i t}+X_{i t} \gamma+\mu_{i}+\varepsilon_{i t}
$$

where $Y_{i t}$ represents either (i) the agricultural land use efficiency calculated based on the hybrid model for county $i$ in period $t$ or (ii) the agricultural product per unit area for county $i$ in period $t$ in robustness test models. $L_{i t}$ is the key independent variable and indicates the change in rural labor input in an individual county driven by off-farm employment. $X_{i t}$ is a matrix of control variables, including local economic development, agricultural status, capital constraints and land scale. $\mu_{i}$ captures unobserved heterogeneity specific to each county, while $\varepsilon_{i t}$ represents the idiosyncratic error. $a, \beta, \gamma$ are vector regression coefficients to be estimated.

The off-farm employment of rural laborers may affect the input-output relationship of agricultural land use in a nonlinear way, as described in section 2. Namely, the quadratic term of the key independent variable, $L_{i t}{ }^{2}$, should be included in the models to capture the nonlinear relationship (Lind and Mehlum, 2010) ${ }^{4}$. Therefore, we adjust the former reduced estimation equation into the following equation:

$$
Y_{i t}=a+\beta L_{i t}+\beta^{\prime} L_{i t}^{2}+X_{i t} \gamma+\mu_{i}+\varepsilon_{i t}
$$

In both equations (7) and (8), $\varepsilon_{i t}$ is assumed to be independent of the regressors and the individual error component. Because the agricultural land use across China's 1,961 counties features underlying differences and the tests of $\varepsilon_{i t}$ entail groupwise heteroscedasticity, autocorrelation within the panel data and cross-section correlation based on linear panel models,

\footnotetext{
${ }^{4}$ We conduct a UTEST module to tentatively test whether $L_{i t}{ }^{2}$ should be included, and the test result shows that $\mathrm{H} 0$ (that there is a U-shaped relationship) cannot be rejected at the significance level of 0.05 .
} 
we use the method proposed by Driscoll and Kraay (1998) to conduct the estimations. This method extends the work of White (1980), Newey and West (1987) to panel data and is based on cross-section averages with standard errors robust to heteroscedasticity, serial correlation and spatial correlation (DK-SE fixed effect model hereafter).

\subsection{Data and variables}

In China's administrative system, the county is the primary unit for land use policy implementation and statistics reporting. Additionally, geographical and cultural characteristics, as well as agricultural land use and the off-farm employment situation, have little variations within counties. Therefore, our empirical analysis uses county-level panel data.

There is a total of 2,854 counties in China as of 2014. They can be classified into four categories: city districts, county-level cities, autonomous counties and ordinary counties. Counties that meet the following three conditions are excluded from this study: (i) the administrative jurisdiction area changes during the time interval; (ii) there is very little agricultural land within the county; (iii) a large proportion of indicators are missing values. This sampling strategy excludes the vast majority of city districts, because they are primarily urban. As shown in Figure 3, our sample consists of data collected from 1,961 counties 5 , which is over $95 \%$ of the population in the county-city, autonomous county, and ordinary county categories. Therefore, our sample is representative of the population.

The urbanization rate in China was only 30.48\% in 1996, and reached 50\% in 2011. Large-scale migration of rural labor to urban areas only began in the mid-1990s in China. According to Cai (2018), surplus rural labor became scarce around 2005, which is potentially the turning points mentioned in Section 3.2. Therefore, we choose the time interval from 2000 to 2014 as our sampling period to cover these important milestones in China's urbanization process. The data are drawn from the China Statistical Yearbook (County-level, 2001-2015) and the annual statistics bulletins issued by the 1,961 county governments.

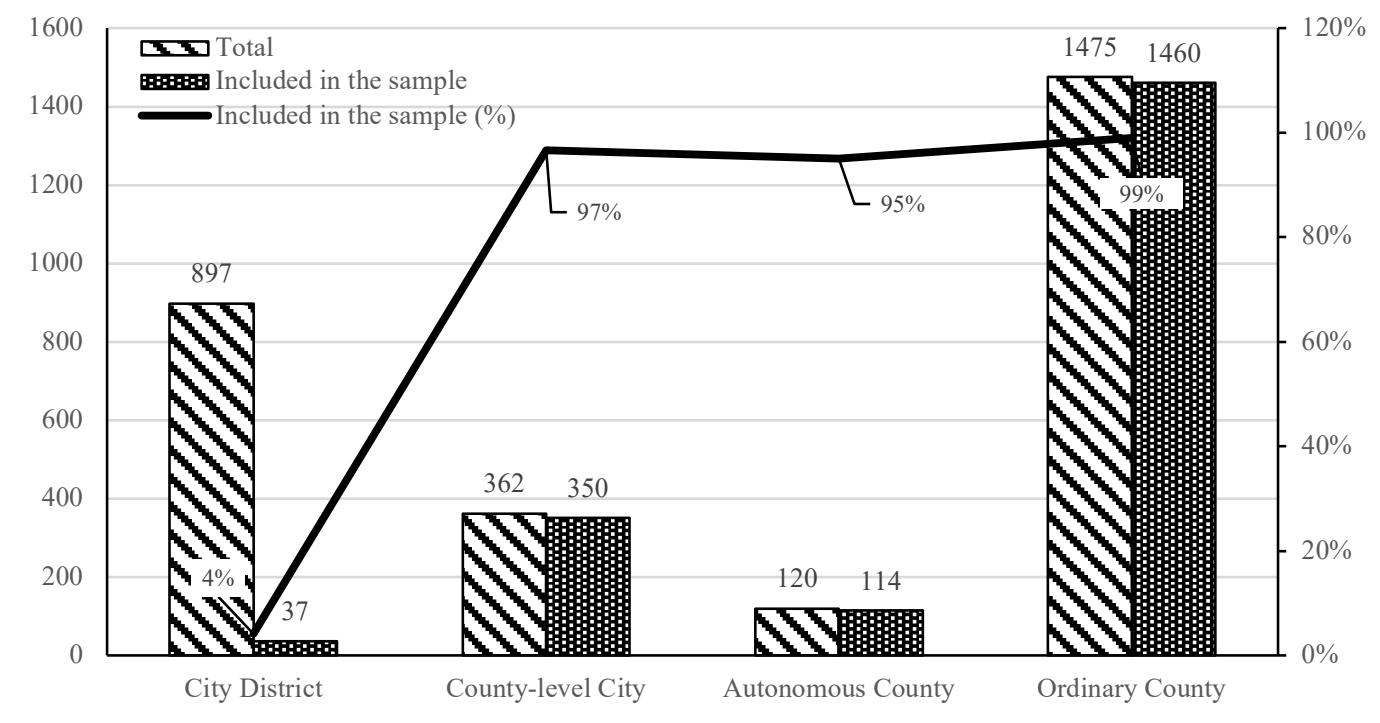

Figure 3. Number and Proportion of Counties Included in the Sample

The dependent variable, agricultural land use efficiency, is estimated by the hybrid model

${ }^{5}$ Hongkong, Macao and Taiwan are not included. 
given in section 3.1. The input factors include land, labor, capital and technology. Specifically, Agriland is the area of agricultural land in a county, and it directly measures the land resources input of agricultural production ${ }^{6}$. Agrilabor represents the amount of rural labor resources actually invested in agricultural production. There are two indicators of capital and technology inputs: Mechi (the total power of agricultural machinery) and Ferti (the amount of chemical fertilizers used in agricultural production. For output factors we include one specific and one overall measurement. Grain, the output of standard crops, is chosen because of its important role in food production and food security in China. Agripro, the gross output value of planting, forestry, animal husbandry and fishery production combined, is used as the overall measurement of agricultural output of a county.

We use the transfer rate of rural labor (pRural), a measurement of the proportion of rural laborers engaged in off-farm employment, as the key independent variable $L_{i t}$ in equation (8). The value of this variable is calculated by using the formula in Liu et al. (2015) and Xu and Zhang (2016) :

$$
\text { pRural }=\frac{\text { LLabor }- \text { Agrilabor }}{\text { rLabor }}
$$

where $r$ Labor is the number of rural laborers who actually participate in production and receive material or monetary income (excluding full-time students, servicemen and people with disability) and Agrilabor is rural labor occupied in planting, forestry, animal husbandry and fishery.

In addition to off-farm employment, we also include six variables to control for their effect on the input-output composition of agricultural land use, as shown in Table 1.gdp_ca is the gross domestic output per capita of a county and is included to control the influence of local economic development on agricultural land use. A higher level of local development is expected to be conducive to not only higher investment in agricultural technology innovation but also a higher probability of agricultural land taking (Jiang et al., 2013). Thus, $g d p \_c a$ could have a nonlinear effect on agricultural land use efficiency. Consequently, we include the squared term of $g d p \_c a$ in our models. gdpratio_se is the ratio between the output values of the secondary and primary industries. gdpratio_te is the ratio between the output values of the tertiary and primary industries. These two variables measure the industry structure and the level of local economic development at the county level. A higher value of these two variables indicates a smaller share or a weaker role of the agricultural sector in the local economy. It may lead to a lack of incentives and interests to improve agricultural productivity. rIncome_ca is the net income of rural households per capita, which controls the influence of capital constraints on efficiency. aLand_hou is the size of arable land area per household, which is used to test the effects of rural land management scale on agricultural input-out. edu_ratio represents the education level of a county, which is included to control the impacts of the quality of rural labor on agricultural land use. The definitions of variables and some descriptive statistics are given in Table 1.

\footnotetext{
${ }^{6}$ China conducted the second national land survey in 2007, and the data of agricultural land use changed greatly before and after the survey due to the change of survey methods. We used a backward extrapolation method to combine the data before and after the 2007.
} 
Table 1. Variable Definitions and Descriptive Statistics

\begin{tabular}{|c|c|c|c|c|c|c|c|}
\hline \multicolumn{2}{|c|}{ Variable } & \multirow{2}{*}{$\begin{array}{l}\text { Description } \\
\text { Agricultural land for planting, forestry, animal } \\
\text { husbandry and fishery }\end{array}$} & \multirow{2}{*}{$\begin{array}{c}\text { Mean } \\
26.5318\end{array}$} & \multirow{2}{*}{$\begin{array}{l}\text { Std. Dev. } \\
36.0115\end{array}$} & \multirow{2}{*}{$\begin{array}{r}\text { Unit } \\
10000 \text { ha }\end{array}$} & \multirow{2}{*}{$\frac{\text { Time period }}{\text { 2001-2014,yearly }}$} & \multirow{2}{*}{$\begin{array}{l}\text { Obs } \\
29415\end{array}$} \\
\hline \multirow{6}{*}{$\begin{array}{l}\text { Variables to } \\
\text { calculate agricultural } \\
\text { land use efficiency } \\
\text { (dependent variable) }\end{array}$} & Agriland & & & & & & \\
\hline & Agrilabor & $\begin{array}{l}\text { Rural laborers occupied in planting, forestry, animal } \\
\text { husbandry and fishery }\end{array}$ & 12.5207 & 9.7501 & 10000 person & 2000-2014, yearly & 29415 \\
\hline & Machi & Total power of agricultural machinery & 32.7981 & 35.0660 & $10000 \mathrm{kw}$ & 2000-2014, yearly & 29415 \\
\hline & Ferti & Consumption of chemical fertilizers & 2.1152 & 2.2128 & 10000 tons & 2000-2014, yearly & 29415 \\
\hline & Grain & Output of grain & 24.4166 & 27.3292 & 10000 tons & 2000-2014, yearly & 29415 \\
\hline & AgriPro & $\begin{array}{l}\text { Gross output value of planting, forestry, animal } \\
\text { husbandry and fishery }\end{array}$ & 1844.4560 & 1771.6200 & million yuan & 2000-2014, yearly & 29415 \\
\hline \multirow{7}{*}{$\begin{array}{l}\text { Independent } \\
\text { variables }\end{array}$} & pRural & $\begin{array}{l}\text { Proportion of rural laborers engaged in off-farm } \\
\text { employment }\end{array}$ & 0.3515 & 0.1722 & - & 2000-2014, yearly & 29415 \\
\hline & $g d p \_c a$ & Gross domestic output per capita of a county & 1.3153 & 1.6252 & $\begin{array}{l}10000 \text { yuan per } \\
\text { capita }\end{array}$ & 2000-2014, yearly & 29415 \\
\hline & gdpratio_se & $\begin{array}{l}\text { Ratio of the output values of secondary and primary } \\
\text { industries }\end{array}$ & 3.2529 & 7.9313 & - & 2000-2014, yearly & 29415 \\
\hline & gdpratio_te & $\begin{array}{l}\text { Ratio of the output values of tertiary and primary } \\
\text { industries }\end{array}$ & 2.5793 & 27.7649 & - & 2000-2014, yearly & 29415 \\
\hline & rIncome_ca & $\begin{array}{l}\text { Net income of rural households per capita of a } \\
\text { county }\end{array}$ & 4655 & 3529 & yuan per capita & 2000-2014, yearly & 29415 \\
\hline & aLand_hou & Cultivated land area per household & 1.1972 & 8.7919 & $\begin{array}{l}\text { ha per } \\
\text { household }\end{array}$ & 2000-2014, yearly & 29415 \\
\hline & edu_ratio & $\begin{array}{l}\text { Ratio of students in middle \& high school to total } \\
\text { population of a county }\end{array}$ & 0.0566 & 0.0175 & - & 2000-2014, yearly & 29415 \\
\hline
\end{tabular}




\section{Empirical findings and discussions}

\subsection{Agricultural land use efficiency}

Using equation (6) and the data introduced in Section 3.2, we calculate the county-level agricultural land use efficiency under variable returns to scale (denoted eff_vrs). For comparison purposes we also calculate the efficiency under constant returns to scale (denoted eff_crs) ${ }^{7}$. The frequency distributions of the two efficiency measurements are very similar, as can be seen in Figure 4. The average values of eff_vrs and eff_crs are 0.2338 and 0.1854 . Both distributions are heavily right-skewed, with a few large outliers in the right tail. This finding justifies our decision to analyze rural land use efficiency at the county level. National, regional, or provincial level data will hide the variation among counties, and average values of agricultural land use efficiency at these higher aggregation levels will overestimate the level of land use efficiency because arithmetic means are biased by outliers. Our empirical strategy recognizes the variation among counties, and will effectively circumvent the above-mentioned issues.
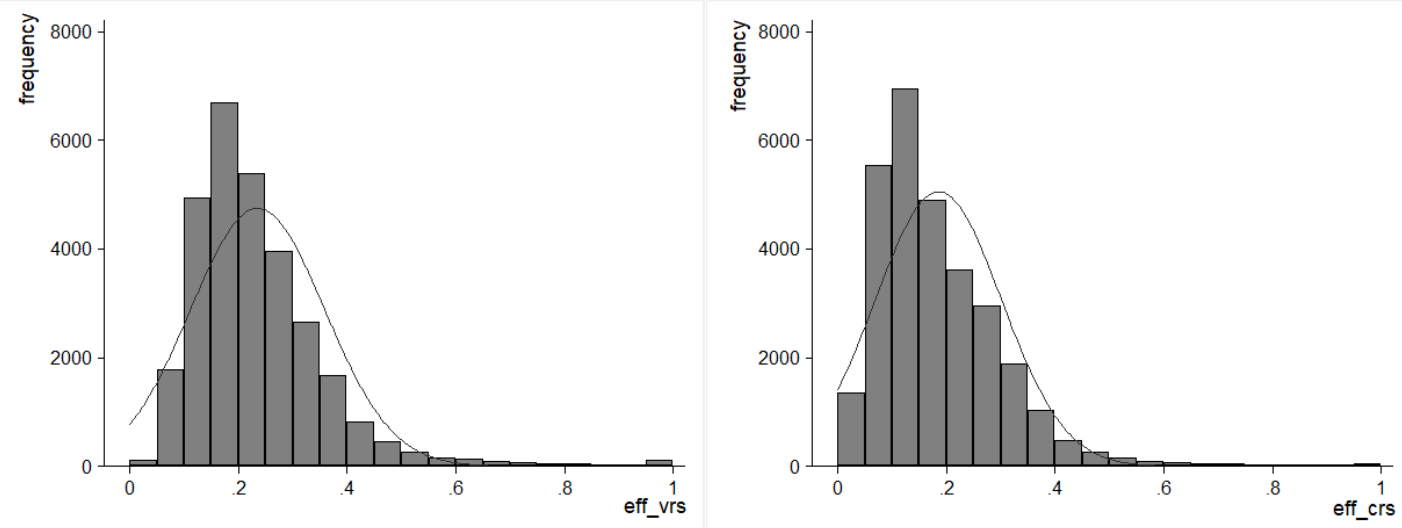

Figure 4. Frequency distribution of county-level agricultural land use efficiency in China

\subsection{The relationship between off-farm employment and land use efficiency}

We use eff_vrs as the dependent variable in the rest of the analysis, because the difference between land use efficiency under variable and constant returns to scale are very similar (see Figure 4). Unit root test results suggest that eff_vrs is stationary. We then use stepwise estimation procedure with eff_vrs as the dependent variable to estimate the DK-SE fixed effects model. The first model that we estimate contains the key independent variable pRural only. Model (2) adds the squared term of pRural, i.e., pRural_sq. In the next steps, both $g d p \_c a$ and its squared term $g d p \_c a \_s q$ are included. Note that both $p R u r a l$ and $g d p \_c a$ are decentralized with their means before entering the analysis. We add in other control variables in the following steps and eventually obtain the Model (6). The regression results are shown in Table 2. The $F$ statistics are significant at the 0.01 level in all models, indicating that the models fit the data well. The coefficient estimates of pRural and its squared term are stable in all models. Our discussions of the empirical results are based on Model (6), which includes all control variables.

We find that off-farm employment (pRural) has a significant nonlinear relationship with agricultural land use efficiency (eff_vrs), because its second order term is statistically significant

\footnotetext{
7 We use MaxDea software to estimate the hybrid-DEA model. eff_crs is calculated by setting the rate of changes constant between production and input factors, whist the variable rate of changes in the calculation of eff_vrs is set by the correlation between projections on the optimal production frontier.
} 
from zero. Because pRural is decentralized with its mean, the coefficient estimates of pRural and pRural)_sq suggests a U-shape relationship between off-farm employment and agricultural land use efficiency. We also run a further analysis by fitting the relationship between pRural and eff_vrs by using the locally weighted scatterplot smoothing (LOWESS) method. The result is depicted in Figure $5^{8}$, in which a U-shape relationship is confirmed. We thus conclude that the effect of off-farm employment on agricultural land use efficiency is U-shaped, and Schultz's model is more in line with China's situation. Additionally, the turning point of the U-shaped curve appears where pRural $=0.2242$ based on model $(6)^{9}$, which is close to the turning point shown in Figure 5. The overall effect of rural laborers' off-farm employment on agricultural land use efficiency changes from a 'drain' to a 'gain', on average, before the transfer rate reaches the average level.

There are several possible reasons behind this U-shaped relationship. First, the rural land management in China is operated in a small-scale land production economy with households as the basic unit. According to Yang et al. (2013), rapid farm mechanization and the development of farm mechanization services did not exist in China until 2004. Therefore, laborer remained to a critical input factor in household agricultural production until there are sufficient supply of specialized labor and large harvesting machines. The transfer of the household labor force has negative effects on agricultural land efficiency when the capital and technology of agricultural production are at a low level and there are no viable substitutions for the lost labor, as observed by Taylor et al. (2003). Second, the rural land right management system in China leads many household members stay behind when one or several members of their family working in urban areas (Zhao, 1999). Rural out-migration in China is the transfer of one or some of the household members instead of the whole family. In other words, it is individual rather than family migration. These remaining family members still work on their farm land and receive remittances from their migrant family members. The remittances are very helpful to improve rural land productivity, only after the wide use of machinery, fertilizer and farm mechanization services are available after 2004. Farm mechanization and the development of farm mechanization services effectively offset the negative impact of the loss of family labor (Zhang et al., 2017). Thus, the net effect of off-farm employment on agricultural land use efficiency turns positive after 2004, which is also verified in the study of Feng et al. (2010) based on a plot-level case study in Southeast China.

Our empirical findings also suggest that the substitution effect of machinery and fertilizer for rural labor has changed from weak to strong in China. This conclusion is consistent with the theory of induced technological change, according to which the adoption of agricultural technology is characterized by a tendency to save relatively scarce production factors (Hayami and Ruttan, 1971). As the labor force becomes a relatively scarce production factor for rural households in China, agricultural technology changes will increasingly favor the substitution of capital and technology for labor as well as labor-saving agricultural production. This induced change could promote the transformation of the agricultural production structure in China, as captured by many recent studies (e.g., Qian et al., 2016; Wang et al., 2017). However, the overall agricultural land use efficiency in China is still at a low level. There is still much room for the improvement of the substitution effect of machinery and fertilizer for rural labor because this effect is constrained by land fragmentation in China ( $\mathrm{Lu}$ et al., 2019).

8 LOWESS is a powerful tool to examine the trend in a scatter plot between two continuous variables and thus provides a reference for checking the relationship between these two variables (Lindsey and Sheather, 2010).

9 Because pRural_sq is decentralized by the mean 0.3515 , the turning point of the curve is calculated by $(0.3515 * 2-0.0605 / 0.2376) / 2$, which equals 0.2242 approximately. 
Table 2. DK-SE fixed effects model estimation results

\begin{tabular}{|c|c|c|c|c|c|c|}
\hline Independent variables & (1) & (2) & (3) & (4) & (5) & (6) \\
\hline \multirow[t]{2}{*}{ pRural } & $0.1274^{* * *}$ & $0.0939^{* * *}$ & $0.0446^{* *}$ & $0.0429^{* *}$ & $0.0557^{* * * *}$ & $0.0605^{* * *}$ \\
\hline & $(5.67)$ & $(5.76)$ & $(2.60)$ & $(2.58)$ & $(4.09)$ & (4.94) \\
\hline \multirow[t]{2}{*}{ pRural_sq } & & $0.3514^{* * *}$ & $0.3102^{* * *}$ & $0.3084^{* * *}$ & $0.2943^{* * *}$ & $0.2376^{* * *}$ \\
\hline & & $(11.70)$ & (12.03) & (11.81) & (10.04) & $(6.61)$ \\
\hline \multirow[t]{2}{*}{$g d p \_c a$} & & & $0.0103^{* * *}$ & $0.0144^{* * *}$ & $0.0168^{* * *}$ & $0.0147^{* * *}$ \\
\hline & & & $(9.27)$ & $(13.30)$ & $(7.56)$ & $(6.51)$ \\
\hline \multirow[t]{2}{*}{$g d p \_c a \_s q$} & & & $-0.0003^{* * *}$ & $-0.0003^{* * *}$ & $-0.0004^{* * *}$ & $-0.0003^{* * *}$ \\
\hline & & & $(-6.73)$ & $(-9.14)$ & $(-7.10)$ & $(-5.24)$ \\
\hline \multirow[t]{2}{*}{ gdpratio_se } & & & & $-0.0023^{* * *}$ & $-0.0024^{* * *}$ & $-0.0023^{* * *}$ \\
\hline & & & & $(-6.81)$ & $(-6.49)$ & $(-5.80)$ \\
\hline \multirow[t]{2}{*}{ gdpratio_te } & & & & $0.0002^{* * *}$ & $0.0002^{* * *}$ & $0.0002^{* * *}$ \\
\hline & & & & $(4.64)$ & $(4.58)$ & (4.40) \\
\hline \multirow[t]{2}{*}{ aLand_hou } & & & & $0.0007^{* *}$ & $0.0007^{* *}$ & $0.0006^{* *}$ \\
\hline & & & & $(2.31)$ & $(2.19)$ & $(2.18)$ \\
\hline \multirow[t]{2}{*}{ lnrIncome_ca } & & & & & 0.0072 & $0.0128^{*}$ \\
\hline & & & & & $(1.29)$ & $(2.01)$ \\
\hline \multirow[t]{2}{*}{ edu_ratio } & & & & & & $-0.0001^{* * *}$ \\
\hline & & & & & & $(-5.33)$ \\
\hline \multirow[t]{2}{*}{ Constant } & $0.1904^{* * *}$ & $0.1918^{* * *}$ & $0.1977^{* * *}$ & $0.1992^{* * *}$ & $0.2506^{* * *}$ & $0.3359^{* * *}$ \\
\hline & $(21.14)$ & $(25.41)$ & $(25.14)$ & $(27.42)$ & $(5.66)$ & (6.49) \\
\hline Obs. & 29415 & 29415 & 29415 & 29415 & 29415 & 29415 \\
\hline$F$ & $32.14^{* * *}$ & $73.94^{* * *}$ & $45.86^{* * *}$ & $84.28^{* * *}$ & $157.32^{* * *}$ & $188.56^{* * *}$ \\
\hline Within- $R^{2}$ & 0.0359 & 0.055 & 0.0692 & 0.0802 & 0.0811 & 0.1010 \\
\hline
\end{tabular}

Notes: a. $t$ statistics in parentheses; $\mathrm{b} .{ }^{*} \mathrm{p}<0.1,{ }^{* *} \mathrm{p}<0.05,{ }^{* * *} \mathrm{p}<0.01 ; \mathrm{c}$. rIncome_ca has been processed with the natural logarithm when performing regressions; $d$. $X \_s q$ represents the quadratic term of the variable $X$ and has been decentralized.

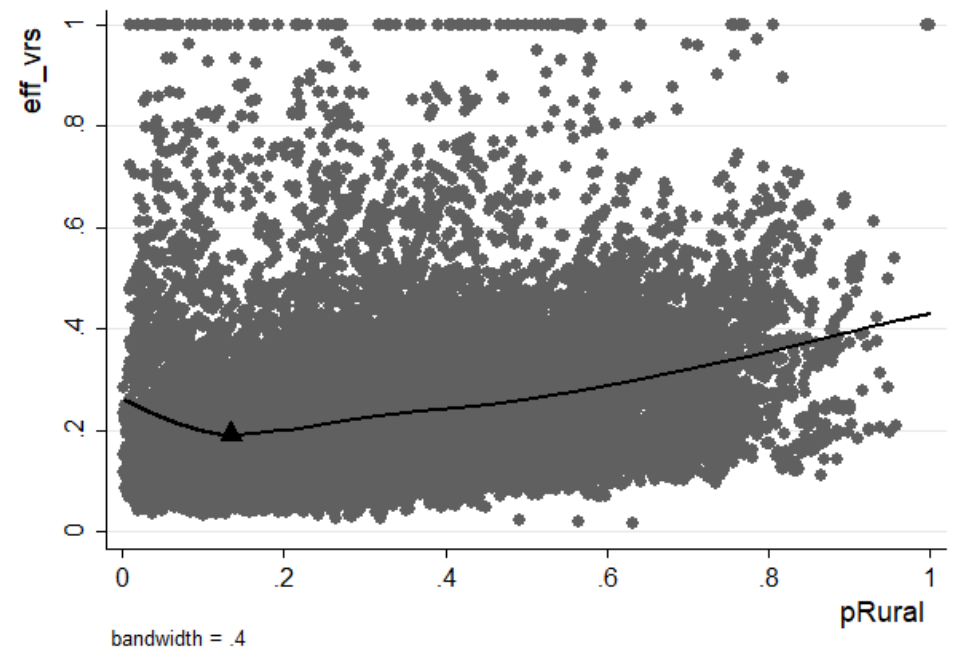

Figure 5. U-shape relationship between $p$ Rural and eff_vrs fitted by LOWESS 


\subsection{Control variables}

The control variables in Model (6) are all significant at the $10 \%$ level. $g d p \_c a$, a proxy of the economic development level of a county that controls the effects of local economic development on agricultural land use, also shows a nonlinear impact on eff_vrs. The inverted U-shaped relationship identified in our model, however, is an interesting result. As the turning point of $g d p \_c a$ is 25.8153 , which is well above its mean of 1.3153 , the relationship between local economic development level and rural land use efficiency is predominantly positive in our sample. The finding is consistent with our expectation that a higher local economic development leads to higher investment in agricultural production, such as local agricultural service stations for peasants, and higher ability for agricultural technology innovation.

gdpratio_se, the ratio between the secondary and primary industry, has a significant and negative relationship with rural land use efficiency. This result coincides with the reality of the relationship between the manufacturing and agriculture industry in China. According to a study by the Group of Chinese Academy of Macroeconomic Research (2018), China has adopted the policy of distorting the price of agricultural products to support the secondary industry in the process of industrialization. This may harm agricultural land use efficiency. gdpratio_te, the ratio between the tertiary and primary industry, has a positive influence on increasing agricultural land use efficiency. An explanation for this is that many branches of the tertiary industry, such as transportation, catering and scientific research and technical services, are closely related to the development of agriculture. Different from the secondary industry, which uses agricultural products as raw materials, the tertiary industry has a more supporting relationship with the development of agriculture (Fitzgerald et al., 2018; Kawagoe et al., 1985). It is also more correlated with modern agricultural production that are related to eco-tourism, organic food, and internet plus (hu-lian-wang +) agriculture (Tu et al., 2018). Thus, it is important to promote industrial transformation and upgrading, which is conducive to the increase in agricultural productivity.

The proxy of agricultural land management scale, aLand_hou, has a positive and significant influence on agricultural land use efficiency, indicating that land fragmentation and small land management scale in China are detrimental to agricultural productivity. This result is consistent with the findings of existing studies on land fragmentation and land transfer in rural China (e.g., Feng, 2008; Feng et al., 2010; Lu et al., 2019). Land management scale works as a constraint of the marginal output of agricultural land. The substitution of agricultural production factors requires corresponding expansion of land management scale to prevent significant declines in the returns to capital and technology. Therefore, it is necessary to promote land transfer through agricultural land system reform, so that the expansion of land management scale is possible. Indeed, the central government has engaged itself in such endeavor mainly through the three rights separation reform (i..e, the separation of ownership right, contract right, and management right of rural land) since 2014 (Wang and Zhang, 2017).

InrIncome_ca has a positive impact on rural land use efficiency. It is significant at the $10 \%$ level only when edu_ratio is included in Model (6). An explanation for the negative impact of $e d u \_r a t i o$, is that a higher level of education does not generate the expected impact on agricultural production but instead results in lower efforts to promote agricultural production efficiency because of the low returns of agriculture under the smallholder production pattern in China. Similar results can be found in a few studies based on surveys of rural households in China, such 
as Wang (2015) and Zhong et al. (2016), in which a more educated household head turns to have a negative impact on the input of agricultural investment or grain production.

\subsection{Robustness check}

In this section we check the sensitivity of our results to two alternative measurements of land use efficiency and a different model estimation method. A total of four models are estimated and the results are reported in Table 3. In Model (7), we use eff_crs, i.e., the efficiency under constant returns to scale, as the dependent variable in the DK-SE fixed effects model. We then use AgriPro_la, the single factor productivity estimation of the gross output value of agricultural product per unit, as the dependent variable in Model (8). Because the estimated efficiency values fall in the interval of $(0,1]$, Models (9) and (10) use Tobit method instead of the DK-SE fixed effects model.

As can be seen in Table 3, the results of alternative models are consistent with the empirical results reported in previous sections. The U-shaped relationship between off-farm employment and rural land use efficiency and the effects of the control variables are maintained in these models. We conclude that the results reported in Sections 4.1 through 4.3 are robust and consistent.

Table 3. Robustness tests results

\begin{tabular}{|c|c|c|c|c|}
\hline Dependent variable & eff_crs & $\triangle$ AgriPro_la & eff_vrs & eff_crs \\
\hline Independent variables & (7) & (8) & (9) & (10) \\
\hline \multirow[t]{2}{*}{ pRural } & $0.0522^{* * *}$ & $0.0124^{* * *}$ & $0.0726^{* * *}$ & $0.0646^{* * *}$ \\
\hline & $(4.00)$ & (3.31) & $(13.92)$ & (13.73) \\
\hline \multirow[t]{2}{*}{ pRural_sq } & $0.1593^{* * *}$ & $0.0411^{* *}$ & $0.2320^{* * *}$ & $0.1524^{* * *}$ \\
\hline & $(5.00)$ & (2.57) & (15.53) & (11.31) \\
\hline \multirow[t]{2}{*}{$g d p \_c a$} & $0.0132^{* * *}$ & $0.0044^{* * *}$ & $0.0142^{* * *}$ & $0.0126^{* * *}$ \\
\hline & (8.16) & (3.37) & (18.94) & (18.60) \\
\hline \multirow[t]{2}{*}{ gdp_casq } & $-0.0003^{* * *}$ & $-0.0001^{* *}$ & $-0.0003^{* * *}$ & $-0.0003^{* * *}$ \\
\hline & $(-6.92)$ & $(-2.82)$ & $(-9.02)$ & $(-7.91)$ \\
\hline \multirow[t]{2}{*}{ gdpratio_se } & $-0.0022^{* * *}$ & $-0.0006^{* * *}$ & $-0.0021^{* * *}$ & $-0.0023^{* * *}$ \\
\hline & $(-6.84)$ & $(-4.31)$ & $(-16.12)$ & $(-19.16)$ \\
\hline \multirow[t]{2}{*}{ gdpratio_te } & $0.0001^{* * *}$ & $0.0001^{* * *}$ & $0.0002^{* * *}$ & $0.0002^{* * *}$ \\
\hline & (4.48) & (3.35) & $(8.27)$ & (6.06) \\
\hline \multirow[t]{2}{*}{ aLand_hou } & $0.0011^{* *}$ & 0.0001 & $0.0007^{* * *}$ & $0.0011^{* * *}$ \\
\hline & (2.91) & (1.54) & (6.96) & (12.4) \\
\hline \multirow[t]{2}{*}{ InrIncome_ca } & 0.0065 & $0.0037^{* *}$ & $0.0127^{* * *}$ & $0.0073^{* * *}$ \\
\hline & $(1.05)$ & $(2.21)$ & $(9.05)$ & $(5.81)$ \\
\hline \multirow[t]{2}{*}{ edu_ratio } & $-0.0001^{* * *}$ & $-0.0711^{* *}$ & $-0.0001^{* * *}$ & $-0.0001^{* * *}$ \\
\hline & $(-4.88)$ & $(-2.74)$ & $(-23.89)$ & $(-22.03)$ \\
\hline \multirow[t]{2}{*}{ Constant } & $0.1313^{* *}$ & -0.0233 & $0.3299^{* * *}$ & $0.1198^{* * *}$ \\
\hline & (2.74) & $(-1.63)$ & $(30.53)$ & (12.29) \\
\hline Obs. & 29415 & 27454 & 29415 & 29415 \\
\hline$F$ & $392.28^{* * *}$ & $75.54^{* * *}$ & - & - \\
\hline
\end{tabular}




Within- $R^{2}$
Wald chi $^{2}$

\section{Policy implications}

Rural labor is a critical input factor in the agriculture sector in China. Rural-urban labor transfer can significantly alter the input-output composition relationship of agricultural land use. Given China's dual urban-rural land system and household registration (hukou) system, the impact of rural labor transfer on agricultural land use efficiency has significant policy implications.

First, effective rural land use policy should take into account the interaction between the household registration system and the rural land use system in China. Our results indicate that the substitution effect of capital and technology for rural labor may contributes to the intertwining effect of rural labor drain and land output gain in China. However, the substitution effect is not as effective as expected because the level of agricultural land use efficiency is still at a low level. Cai and Wang (2016) and $\mathrm{Lu}$ et al. (2019) argue that the smallholder management scale and land fragmentation in rural China reduce the marginal productivity of agricultural labor, limit the substitution effect of capital, and eventually result in the low competitiveness of agriculture. Thus, it is necessary to promote agricultural land transfer and expand the land management scale in rural China. To this end, the Chinese government has introduced a series of reforms in recent years, such as the Three Rights Separation Reform, the issuance of land rights certificates, and the mortgage of land management rights (Wang and Zhang, 2017). However, the effectiveness of these reforms has been hindered by the dual urban-rural hukou system, which leads to the individual, rather than the family, based migration pattern of rural labor. Consequently, the willingness for remaining family members to transfer the rights of their farmland is quite low. Therefore, a joint reform of the hukou and rural land system in China is needed to promote the transformation from individual based migration to family-based migration, and to improve the scale of rural land use and management.

Second, the U-shaped relationship between the rural-urban transfer of rural labor and agricultural land use efficiency also indicates that there is much room for rural laborers to leave the countryside. Gai et al. (2014) point out that the connotation of rural surplus labor is relative to the actual demand of agricultural production. If the positive income effect is strong enough to counterbalance the negative impact of lost labor, there will be off-farm employment of rural laborers (Feng et al., 2010). This is in line with the fact that China has not yet completed the reallocation of labor that matches its economic structure. With more rural laborers engaged in off-farm employment, agricultural land use would develop towards a labor-saving production mode (Chen et al., 2014). Thus, local government in China could focus resources on promoting induced technology change driven by the off-farm employment of rural laborers. This approach could effectively support the transformation of the agricultural land use structure in China.

In summary, rural land use policies in China should facilitate coordinated actions on three important factors in rural land market: the people, the place, and the product. Improving 
rural-urban mobility helps rural residents to move to urban areas. This is the 'people' factor. Establishing a well-functioning rural land rights market will facilitate the transaction and transfer of land rights. This is the 'place' factor. Finally, the confirmation, registration and protection of land rights ensure that there are good 'products' in the rural land market. Using this framework, we evaluate policies related to rural land use from 2014 onwards $^{10}$. In Table 4, We listed a total of 20 government policies that are directly related to rural land use between 2014 and 2020. In the last three columns of Table 4, we indicate whether each document has clauses concerning any of the three factors mentioned above. There are 9,8 , and 12 documents that deal with rural-urban mobility, rural land market development, and rural land rights, respectively. For example, the Several Opinions of the CPC Central Committee and the State Council on Comprehensively Deepening Rural Reform and Accelerating Agricultural Modernization (No.1 Central Document in 2014) in 2014 contains important instructions to support rural residents to have the rights to profit from, transfer, and mortgage their land use rights. Therefore, the document checks the boxes for the second and the third factor.

Table 4 indicates that the three important policy areas are covered reasonably evenly, which rural land rights receiving about 30\% more attention than the other two areas. However, Statistics in Table 4 is a crude measurement of policy coverage on the three areas, as it does not reflect how many instructions and regulations are specified in those documents. Such information can only be revealed by content analysis, i.e., full text analysis of the 20 documents to find out the frequency of and the interrelationship among the three factors. Consequently, we carried out content analysis on the original content (in Chinese) in these documents. The results are translated into English and presented in Figures 6 and 7. Figure 6 is a word cloud chart of the frequency of keywords in these documents. High frequency words are highlighted in large font size in the chart. Figure 7 is a network relationship chart to illustrate the links between identified keywords in the 20 policy documents. The size of the circle represents the level of connectedness of each keyword (i.e., how many connections that a node has), and the thickness of the lines indicates the strength of connection. These two figures visualize the areas that are emphasized and the connections between them in these documents.

Figure 6 suggests that keywords about land use rights, such as "land management right", "contracted Land", "land transfer", and "agricultural transfer" appeared the most in these policy documents. Rural-urban mobility related keywords, such as "household registration system", "citizenization" 11 ", and "migrant workers" also received good coverage, although the frequency as indicated by the font size is relatively smaller. Keywords on rural land right market development are small both in number and in frequency. For example, "mortgage", "collective operation land marketing" are related to the development of rural land right market. The size of these keywords is much smaller when compared with those from the other two categories. The pattern identified in Figure 6 indicates that although rural land right market development was included in almost half of the documents reviewed, the dealing of this issue remains light-touched when compared with

\footnotetext{
10 The National Bureau of Statistics of China made changes in its household survey methods in 2013 and its way of collecting agricultural land in 2017. As a result, we cannot obtain compatible statistics on household income (rlncome_ca) and agricultural land (Agriland) at the county level after 2014, and our empirical analysis used data between 2000 and 2014 only. Details of these changes can be found at www.stats.gov.cn/tjsj/sjjd/201402/t20140 224_515109.html, and www.gov.cn/zhengce/content/2017-10/16/content_5232104.htm.

11 In China this term means the change from rural to urban resident status. This is a unique term under the dual rural-urban resident registration system, where the change from rural to urban resident status has been under strict control.
} 
policies on the other two areas.

Figure 7 confirms the pattern identified in Figure 6 . We allow the software ${ }^{12}$ to identify a larger number of keywords than that in the wordcloud analysis in order to best review underlying connections. First of all, rural land rights has the most number of keywords identified by the system, and the most connected keywords are almost all from this category. For example, the circles of "land contracting rights", "three-rights separation reform", "land management rights", and "collective ownership" are among the largest and they are connected to many other nodes in Figure 7.

Second, rural-urban mobility issues also have a good number of keywords identified by the system and the connectiveness of these nodes are modest when compared with those about rural land rights. For example, "new population management methods", "household registration system", "stable employment", and "new residence registration" are all in the rural-urban mobility category. The size of the circle is relatively smaller, which means these keywords are not as strongly connected with other keywords as those in the rural land rights category.

Finally, rural land right market development has the weakest connectedness among the three categories. Keywords such as "mortgage loan for land management rights", "land transfer and mortgage", and "land mortgage" are in this category. The size of the circle of these keywords are much smaller than those in the other two categories. The clear distinction in the size of circles among the three categories suggests that many of the policies are still designed in isolation. For example, the strong connectedness of rural land rights keywords comes from the inter-connection among themselves, not with keywords from other categories. Otherwise the connectiveness will be more evenly distributed among keywords from the three categories. The lack of coordinated policies among the three areas is also consistent with existing literature. For example, there have been calls for coordinated household registration system reform and rural land reform (see, for example, Li et al., 2018; Wang et al., 2011; Zhou et al., 2020). There are also studies showing the need to develop rural land rights market in China's rural land reforms (Andreas and Zhan, 2016; Gao et al., 2020; Wu et al., 2018).

Our evaluation of rural land use policy between 2014 and 2020 comes to two conclusions. Firstly, the general direction of rural land use policy making is encouraging. The 20 policy documents cover the three important factors to improve rural land use efficiency. This is reflected by the good coverage of rural-urban mobility, rural land rights market development, and rural land rights in the 20 policy documents reviewed. Second, a synergy among the three factors has not been created by these policies. Current policy documents may not be able to support decisions that affect more than one of the three key areas. Coordinated actions to improve rural-urban mobility, to support the development of rural land right market, and to protect rural land rights are essential to improve rural land productivity. This should be the focus of rural land use policy making in China. Our analysis shows that the central government has already recognized the importance of such a strategy by covering all three areas in recent policy documents. More importantly, the practice between 2014 and 2020 has laid a solid foundation to achieve the long-term goal: a synergy among people, place, and product in rural land market, and ultimately the efficient and sustainable use of rural land.

12 We used an open source visualization platform, Gephi, to analyze the content of policy documents. Details of the software and the platform can be found at https://gephi.org. 
Table 4: Policy Analysis (2013 - 2020)

\begin{tabular}{|c|c|c|c|c|c|}
\hline No. & Policy Document & Year & $\begin{array}{c}\text { Rural-Urban } \\
\text { Mobility }\end{array}$ & $\begin{array}{l}\text { Rural Land } \\
\text { Market } \\
\text { Development }\end{array}$ & $\begin{array}{l}\text { Rural } \\
\text { Land } \\
\text { Rights }\end{array}$ \\
\hline 1 & $\begin{array}{l}\text { Several Opinions of the CPC Central Committee and the State Council on Comprehensively Deepening Rural Reform and } \\
\text { Accelerating Agricultural Modernization (No.1 Central Document in 2014) }\end{array}$ & 2014 & & $\checkmark$ & $\checkmark$ \\
\hline 2 & The National New-type Urbanization Plan (2014-2020) & 2014 & $\checkmark$ & & $\checkmark$ \\
\hline 3 & Opinions on Further Promoting the Reform of the Household Registration System（Delivered by the State Council） & 2014 & $\checkmark$ & & \\
\hline 4 & Opinions on Further Improving the Work of Serving Migrant Workers （Delivered by the State Council） & 2014 & $\checkmark$ & & \\
\hline 5 & $\begin{array}{l}\text { Several Opinions of the CPC Central Committee and the State Council on strengthening reform and innovation to speed up } \\
\text { agricultural modernization (No.1 Central Document in 2015) }\end{array}$ & 2015 & & $\checkmark$ & $\checkmark$ \\
\hline 6 & $\begin{array}{l}\text { Decision of the Standing Committee of the National People's Congress on Authorizing the State Council to Temporarily Adjust } \\
\text { and Implement the Relevant Laws and Regulations in the Administrative Areas of } 33 \text { Pilot Counties (cities and districts), including } \\
\text { Daxing District, Beijing }\end{array}$ & 2015 & & & $\checkmark$ \\
\hline 7 & $\begin{array}{l}\text { Guiding opinions of the state council on the pilot projects of mortgage loans for the management of contracted land in rural areas } \\
\text { and for the housing property rights of farmers (Delivered by the State Council) }\end{array}$ & 2015 & & $\checkmark$ & \\
\hline 8 & $\begin{array}{l}\text { Decision of the Standing Committee of the National People's Congress on Authorizing the State Council to Temporarily Adjust } \\
\text { and Implement Relevant Laws and Regulations in the Administrative Areas of } 232 \text { Pilot Counties (cities and districts), including } \\
\text { Daxing District, Beijing, and Jixian County, Tianjin }\end{array}$ & 2015 & & & $\checkmark$ \\
\hline 9 & $\begin{array}{l}\text { Several Opinions of the CPC Central Committee and the State Council on Implementing the New Concept of Development to } \\
\text { Accelerate Agricultural Modernization and Realize the Goal of Building a Moderately Prosperous Society in All Respects (No.1 } \\
\text { Central Document in 2016) }\end{array}$ & 2016 & $\checkmark$ & & $\checkmark$ \\
\hline 10 & Promoting the Settlement of 100 Million Non-Resident Population in Cities (Delivered by the General Office of the State Council) & 2016 & $\checkmark$ & & \\
\hline 11 & $\begin{array}{l}\text { Several Opinions of the CPC Central Committee and the State Council on Improving the Separating Method of Ownership Rights, } \\
\text { Contracting Rights and Management Rights of Rural Land }\end{array}$ & 2016 & & & $\checkmark$ \\
\hline
\end{tabular}




\begin{tabular}{|c|c|c|c|c|c|}
\hline No. & Policy Document & Year & $\begin{array}{c}\text { Rural-Urban } \\
\text { Mobility }\end{array}$ & $\begin{array}{l}\text { Rural Land } \\
\text { Market } \\
\text { Development }\end{array}$ & $\begin{array}{l}\text { Rural } \\
\text { Land } \\
\text { Rights }\end{array}$ \\
\hline 12 & $\begin{array}{l}\text { Several Opinions of the CPC Central Committee and the State Council on Implementing the Deepening Supply-side Structural } \\
\text { Reform in Agriculture and Accelerating the Cultivation of New Drivers for Agricultural and Rural Development (No.1 Central } \\
\text { Document in 2017) }\end{array}$ & 2017 & & $\checkmark$ & \\
\hline 13 & $\begin{array}{l}\text { Amendments to the Rural Land Contracting Law of the People's Republic of China (Delivered by the Standing Committee of the } \\
\text { National People's Congress) }\end{array}$ & 2017 & $\checkmark$ & & \\
\hline 14 & $\begin{array}{l}\text { Secure a Decisive Victory in Building a Moderately Prosperous Society in All Respects and Strive for the Great Success of } \\
\text { Socialism with Chinese Characteristics for a New Era (Delivered at the 19th National Congress of the Communist Party of China) }\end{array}$ & 2017 & & & $\checkmark$ \\
\hline 15 & $\begin{array}{l}\text { Opinions of the CPC Central Committee and the State Council on the Implementation of the Rural Revitalization Strategy (No.1 } \\
\text { Central Document in 2018) }\end{array}$ & 2018 & $\checkmark$ & $\checkmark$ & $\checkmark$ \\
\hline 16 & the Plan for the Rural Revitalization Strategy (2018-2022) (Delivered by the CPC Central Committee and the State Council) & 2018 & & $\checkmark$ & $\checkmark$ \\
\hline 17 & $\begin{array}{l}\text { Several Opinions of the CPC Central Committee and the State Council on Prioritizing the Development of Agriculture and Rural } \\
\text { Areas to Address the Issues Relating to Agriculture, Rural Areas and Rural People (No.1 Central Document in 2019) }\end{array}$ & 2019 & $\checkmark$ & $\checkmark$ & $\checkmark$ \\
\hline 18 & $\begin{array}{l}\text { Opinions of the CPC Central Committee and the State Council on Establishing and Improving Systems, Mechanisms and Policy } \\
\text { systems for Integrated Urban-rural Development }\end{array}$ & 2019 & $\checkmark$ & & \\
\hline 19 & $\begin{array}{l}\text { Amendments to the Land Administration Law of the People's Republic of China (Delivered by the Standing Committee of the } \\
\text { National People's Congress) }\end{array}$ & 2019 & & $\checkmark$ & \\
\hline 20 & $\begin{array}{l}\text { Opinions of the CPC Central Committee and the State Council on Ensuring that Key Work in the Areas of Agriculture, Rural } \\
\text { Areas and Rural People is Well Carried out to Ensure the Realization of a Moderately Prosperous Society in All Respects as } \\
\text { Scheduled (No.1 Central Document in 2020) }\end{array}$ & 2020 & & & $\checkmark$ \\
\hline
\end{tabular}




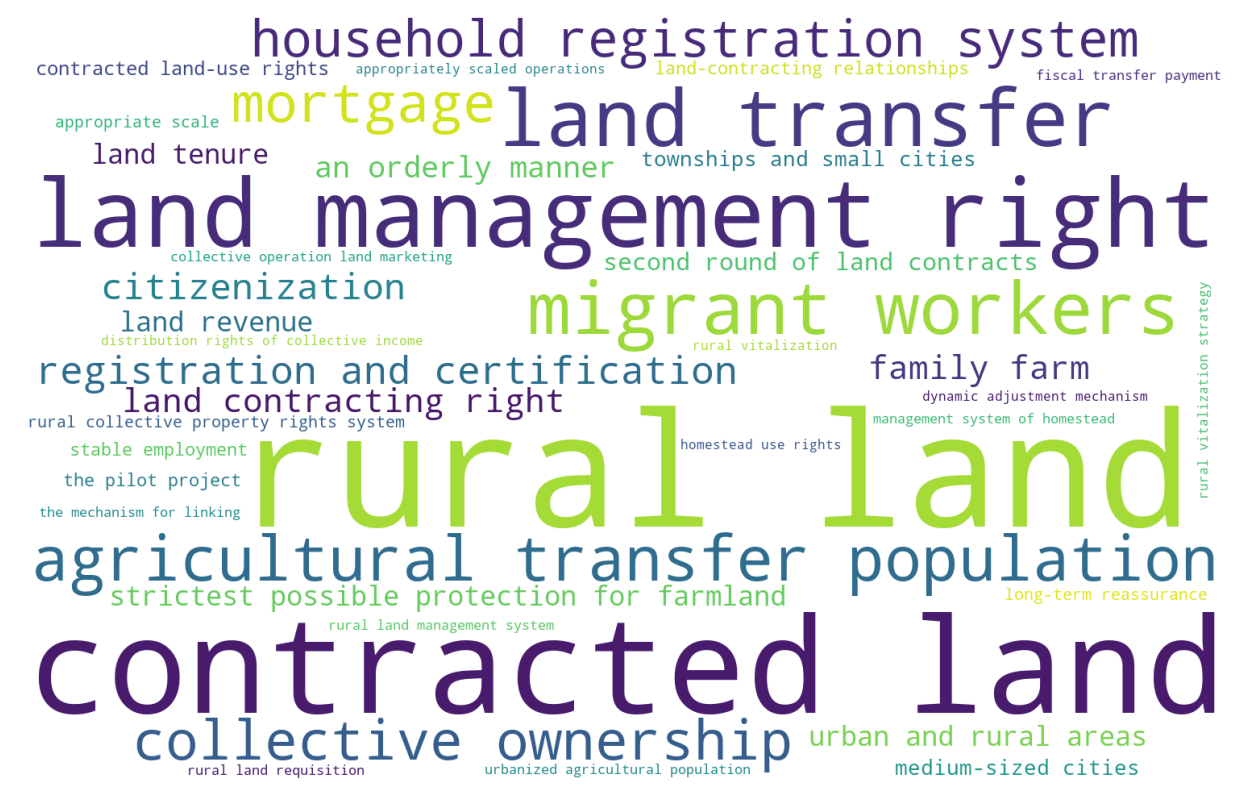

Figure 6: Word Cloud Analysis of Related Policies between 2014 and 2020

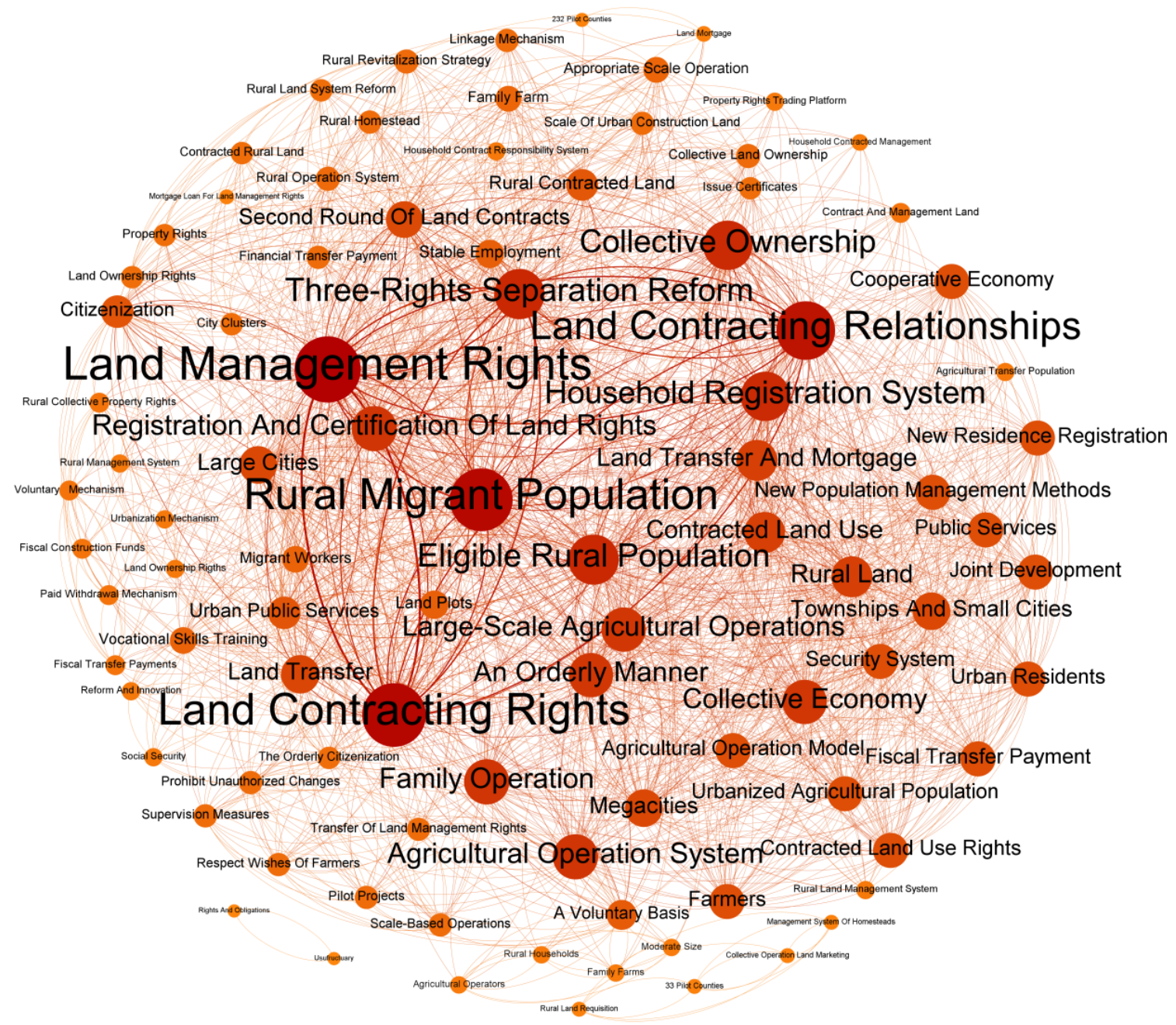

Figure 7: Network Relationship Analysis of Related Policies between 2014 and 2020 


\section{Conclusions}

We develop a theoretical framework to isolate the net effect of off-farm employment on rural land use efficiency. DK-SE fixed effects models are estimated using the panel data of 1,961 counties in China. We find that the impact of rural laborers' off-farm employment on agricultural land use efficiency in China follow a U-shaped pattern. When off-farm employment ratio is below $22.4 \%$, its impact on rural land use efficiency is negative. The relationship changes direct when off-farm employment ratio increases above this level. In other words, for counties with low off-farm employment ratio, having farmers engaging in non-agriculture activities will hurt rural land use efficiency. However, this negative impact diminishes as the proportion of rural laborers engaged in off-farm employment increases, and will eventually turn into a positive effect. If local government focuses their resources on encouraging and supporting remaining rural laborers to adopt new technologies and machineries, agriculture production will improve even if there have been significant outflows of rural laborers.

Our study sheds new light on the complex relationship between non-agricultural employment of rural labor force and rural land use in China. The real question that Chinese policy makers should ask themselves is not "who will plant the crops in the future", but "how to plant crops and increase agricultural land use efficiency in the future". Tying farmers to their rural land can only improve land use efficiency when local economy is dominated by the agriculture sector (i.e., the proportion of rural laborers engaged in off-farm employment is at a low level). When more rural laborers work off-farm, the labor shortage and their remittances to family members in their hometown can push and pull the households to adopt advanced technology and new equipment in agriculture production. This will eventually lead to the improvement of rural land use efficiency. Our policy analysis also shows that rural land use policies between 2014 and 2020 covers the three important areas to improve rural land use efficiency, that is, rural-urban mobility, rural land rights market development, and rural land rights protection. Although a synergy among the three areas has not yet been achieved, the central government has already put in place policies to enable and support coordinated actions in the three areas in future. 


\section{References}

Abler, D.G., Sukhatme, V.A., 2006. The "Efficient but Poor" Hypothesis. Rev. Agric. Econ. 28, 338343. doi:10.1111/j.1467-9353.2006.00296.x

Allen, R.C., 2000. Economic structure and agricultural productivity in Europe, 1300-1800. Eur. Rev. Econ. Hist. 4, 1-25. doi:10.1017/s1361491600000125

Andreas, J., Zhan, S., 2016. Hukou and land: Market reform and rural displacement in China. J. Peasant Stud. 43, 798-827. doi:10.1080/03066150.2015.1078317

Boland, A., 2000. Feeding fears: Competing discourses of interdependency, sovereignty, and China's food security. Polit. Geogr. 19, 55-76. doi:10.1016/S0962-6298(99)00035-9

Cai, F., 2018. Has China's labor mobility exhausted its momentum? Chinese Rural Econ. 2-13(in Chinese).

Cai, F., Wang, M., 2016. Challenges facing China's agriculture as it moves towards a new development stage. Econ. Res. J. 14-26(in Chinese).

Chang, P., 2012. Agricultue and Industrialization. CITIC Press, Beijing.

Chauvin, J.P., Glaeser, E., Ma, Y., Tobio, K., 2017. What is different about urbanization in rich and poor countries? Cities in Brazil, China, India and the United States. J. Urban Econ. 98, 17-49. doi:10.1016/j.jue.2016.05.003

Chen, R., Ye, C., Cai, Y., Xing, X., Chen, Q., 2014. The impact of rural out-migration on land use transition in China: Past, present and trend. Land use policy 40, 101-110. doi:10.1016/j.landusepol.2013.10.003

de Brauw, A., Mueller, V., Lee, H.L., 2014. The role of rural-urban migration in the structural transformation of Sub-Saharan Africa. World Dev. 63, 33-42. doi:10.1016/j.worlddev.2013.10.013

de Brauw, A., Rozelle, S., 2008. Migration and household investment in rural China. China Econ. Rev. 19, 320-335. doi:10.1016/j.chieco.2006.10.004

Driscoll, J.C., Kraay, A.C., 1998. Consistent Covariance Matrix Estimation with Spatially Dependent Panel Data. Rev. Econ. Stat. 80, 549-560. doi:10.1162/003465398557825

Fei, J.C.H., Rains, G., 1964. Development of the Labor Surplus Economy: Theory and Policy. Richard D. Irwin, Homewood.

Feng, S., 2008. Land rental, off-farm employment and technical efficiency of farm households in Jiangxi Province, China. NJAS - Wageningen J. Life Sci. 55, 363-378. doi:10.1016/S1573-5214(08)80026-7

Feng, S., Heerink, N., Ruben, R., Qu, F., 2010. Land rental market, off-farm employment and agricultural production in Southeast China: A plot-level case study. China Econ. Rev. 21, 598606. doi:10.1016/j.chieco.2010.06.002

Fitzgerald, D., Onaga, L., Pawley, E., Phillips, D., 2018. Agricultural history and the story of Science. Agric. Hist. 92, 569-604. doi:10.3098/ah.2018.092.4.569

Gai, Q., Zhu, X., Shi, Q., 2014. Labor's migration and Chinese agricultural production. China Econ. Q. 13, 1147-1170(in Chinese). doi:10.13821/j.cnki.ceq.2014.03.015

Gao, J., Liu, Y., Chen, J., 2020. China's initiatives towards rural land system reform. Land use policy 94, 1-4. doi:10.1016/j.landusepol.2020.104567

Glaeser, E.L., 2014. A world of cities: The causes and consequences of urbanization in poorer countries. J. Eur. Econ. Assoc. 12, 1154-1199. doi:10.1111/jeea.12100

Group of Chinese Academy of Macroeconomic Research, 2018. Relationship evolution between 
industry and agriculture over the past 40 years of Reform and Opening-up in China: From mitigation to integration. Reform 39-51(in Chinese). doi:j.cnki/refo201810004

Hayami, Y., Ruttan, V.W., 1971. Agricultural development: an international perspective. Baltimore, Md/London: The Johns Hopkins Press.

Helfand, S.M., 2003. Farm size and the determinants of productive efficiency in the Brazilian Center-West, in: The 25th International Conference of Agricultural Economists(IAAE). pp. 605612. doi:10.1016/j.agecon.2004.09.021

Ji, Y., Hu, X., Zhu, J., Zhong, F., 2017. Demographic change and its impact on farmers' field production decisions. China Econ. Rev. 43, 64-71. doi:10.1016/j.chieco.2017.01.006

Ji, Y., Yu, X., Zhong, F., 2012. Machinery investment decision and off-farm employment in rural China. China Econ. Rev. 23, 71-80. doi:10.1016/j.chieco.2011.08.001

Jiang, L., Deng, X., Seto, K.C., 2013. The impact of urban expansion on agricultural land use intensity in China. Land use policy 35, 33-39. doi:10.1016/j.landusepol.2013.04.011

Kawagoe, T., Hayami, Y., Ruttan, V.W., 1985. The intercountry agricultural production function and productivity differences among countries. J. Dev. Econ. 19, 113-132. doi:10.1016/0304-3878(85)90041-0

Ledent, J., 1982. Rural-urban migration, urbanization, and economic development. Econ. Dev. Cult. Change 30, 507-538.

Lewis, W.A., 1954. Economic Development with Unlimited Supplies of Labour. Manchester Sch. Econ. Soc. Stud. 22, 139-191. doi:10.1111/j.1467-9957.1954.tb00021.x

Li, J., Li, Y., Zhang, W., Yu, J., 2018. Imbalanced ownership transformation and land use within an urban area: A case study of Beijing. Land use policy 74, 240-247. doi:10.1016/j.landusepol.2017.08.024

Lind, J.T., Mehlum, H., 2010. With or without U? The appropriate test for a U-shaped relationship. Oxf. Bull. Econ. Stat. 72, 109-118. doi:10.1111/j.1468-0084.2009.00569.x

Lindsey, C., Sheather, S., 2010. Model fit assessment via marginal model plots. Stata J. 10, 215-225. doi:10.1177/1536867X1001000203

Liu, S., 2018. The structure of and changes to China's land system, in: Garnaut, R., Song, L., Cai, F. (Eds.), China's 40 Years of Reform and Development: 1978-2018. ANU Press, pp. 427-454. doi:10.22459/cyrd.07.2018.22

Liu, X., Zhang, X., Fang, W., 2015. Distribution effects of the infrastructure on urban and rural income: A perspective of rural labor transfer. J. World Econ. 145-170(in Chinese).

Liu, Y., Li, Y., 2017. Revitalize the world's countryside. Nature 548, 275-277. doi:10.1038/548275a

Lu, H., Xie, H., Yao, G., 2019. Impact of land fragmentation on marginal productivity of agricultural labor and non-agricultural labor supply: A case study of Jiangsu, China. Habitat Int. 83, 65-72. doi:10.1016/j.habitatint.2018.11.004

Mendola, M., 2008. Migration and technological change in rural households: Complements or substitutes? J. Dev. Econ. 85, 150-175. doi:10.1016/j.jdeveco.2006.07.003

Mubarak, A., Derek, B., 1991. Economic efficiency of small farmers in a changing world: A survey of recent evidence. J. Int. Dev. 3, 1-27. doi:10.1002/jid.4010030102

Newey, W.K., West, K.D., 1987. A Simple , Positive Semi-Definite , Heteroskedasticity and Autocorrelation Consistent Covariance Matrix. Econometrica 55, 703-708. doi:10.2307/1913610

Phimister, E., Roberts, D., 2006. The effect of off-farm work on the intensity of agricultural production. Environ. Resour. Econ. 34, 493-515. doi:10.1007/s10640-006-0012-1 
Qian, W., Wang, D., Zheng, L., 2016. The impact of migration on agricultural restructuring: Evidence from Jiangxi Province in China. J. Rural Stud. 47, 542-551. doi:10.1016/j.jrurstud.2016.07.024

Reddy, N.B.K., Ramanaiah, Y.V., 2002. Changes in agricultural land use efficiency in Andhra Pradesh. Land use policy 2, 210-216. doi:10.1016/0264-8377(85)90069-9

Rozelle, S., Taylor, J.E., de Brauw, A., 1999. Migration , Remittances , and Agricultural Productivity in China. Am. Econ. Rev. 89, 287-291.

Schultz, T.W., 1964. Transforming Tradational Agriculture. Yale University Press, New Haven.

Smil, V., 1995. Who Will Feed China ? China Q. 801-813.

Taylor, J.E., Rozelle, S., de Brauw, A., 2003. Migration and Incomes in Source Communities: A New Economics of Migration Perspective from China. Econ. Dev. Cult. Change 52, 75-101. doi: $10.1086 / 428715$

the Central People's Government of the People's Republic of China, O., 2004. Land Administration Law of the People's Republic of China. http://www.gov.cn/banshi/2005-05/26/content_989.htm, the People's Republic of China.

Tu, S., Long, H., Zhang, Y., Ge, D., Qu, Y., 2018. Rural restructuring at village level under rapid urbanization in metropolitan suburbs of China and its implications for innovations in land use policy. Habitat Int. 77, 143-152. doi:10.1016/j.habitatint.2017.12.001

Wang, H., Tong, J., Su, F., Wei, G., Tao, R., 2011. To reallocate or not: Reconsidering the dilemma in China's agricultural land tenure policy. Land use policy $28,805-814$. doi:10.1016/j.landusepol.2011.01.006

Wang, Q., Zhang, X., 2017. Three rights separation: China 's proposed rural land rights reform and four types of local trials. Land use policy 63, 111-121. doi:10.1016/j.landusepol.2017.01.027

Wang, X., Huang, J., Rozelle, S., 2017. Off-farm employment and agricultural specialization in China. China Econ. Rev. 42, 155-165. doi:10.1016/j.chieco.2016.09.004

Wang, Z., 2015. Does migration make rural household less productive? Stat. Res. 32, 54-61(in Chinese). doi:10.19343/j.cnki.11-1302/c.2015.03.007

White, H., 1980. A heteroskedasticity-consistent covariance matrix estimator and a direct test for heteroskedasticity. Econometrica 48, 817-838. doi:10.2307/1912934

Wu, Y., Mo, Z., Peng, Y., Skitmore, M., 2018. Market-driven land nationalization in China: A new system for the capitalization of rural homesteads. Land use policy 70, 559-569. doi:10.1016/j.landusepol.2017.10.003

Xu, D., Deng, X., Guo, S., Liu, S., 2019. Labor migration and farmland abandonment in rural China: Empirical results and policy implications. J. Environ. Manage. 232, 738-750. doi:10.1016/j.jenvman.2018.11.136

Xu, J., Zhang, X., 2016. Inprovement of agricultural productivity,transfer of rural labor, and the intergrated development of industry and agriculture. Manage. World 76-97(in Chinese).

$\mathrm{Xu}, \mathrm{Y} ., 2$ 2014. Agriculture and industrialization [WWW Document]. Pap. URL https://m.thepaper.cn/newsDetail_forward_1280499

Yang, J., Huang, Z., Zhang, X., Reardon, T., 2013. The Rapid rise of cross-regional agricultural mechanization services in China. Am. J. Agric. Econ. 95, 1245-1251. doi:10.1093/ajae/a

Zhang, X., Yang, J., Thomas, R., 2017. Mechanization outsourcing clusters and division of labor in Chinese agriculture. China Econ. Rev. 43, 184-195. doi:10.1016/j.chieco.2017.01.012

Zhang, X., Yang, J., Wang, S., 2011. China has reached the Lewis turning point. China Econ. Rev. 22, 542-554. doi:10.1016/j.chieco.2011.07.002 
Zhao, Q., Zhang, Z., 2019. Analysis on the changing characteristics and causes of county-level agricultural land use efficiency in China. China Popul. Resour. Environ. 29, 7-86(in Chinese). doi:10.12062/cpre.20180932

Zhao, Y., 1999. Leaving the Countryside : Rural-To-Urban Migration Decisions in China. Am. Econ. Rev. 89, 281-286.

Zhong, F., Lu, W., Xu, Z., 2016. Is it not conducive to food production for rural labor to be occupied in off-farm empolyment? Chinese Rural Econ. 36-47(in Chinese).

Zhou, Y., Li, X., Liu, Y., 2020. Rural land system reforms in China: History, issues, measures and prospects. Land use policy 91, 1-15. doi:10.1016/j.landusepol.2019.104330 